\title{
Mathematical Model for Optimizing Charge and Heel Levels in Steel Remelting Induction Furnace for Foundry Shop
}

\author{
O.K. Abubakre and R.A. Muriana* \\ Mechanical Engineering Department, Federal University of Technology, Minna, Nigeria \\ *Corresponding Author: mraremu@yahoo.com
}

\begin{abstract}
Heat energy balance equation in an induction furnace was developed along with computer programme (model) written in basic programming language to optimize the charge/heel level in the furnace, using the hypoeutectic AISI-SAE 1042 alloy steel as charge material. Time and cost of electrical energy consumption were considered as the decision variables. The model results showed that Charge (solid scrap) and Heel (molten steel) levels of ratio 3:2 was the optimum for an economical productivity.
\end{abstract}

\section{INTRODUCTION}

Considerable amount of rejects at the end of a production line in an alloy steel based plant, turnings and borings from machine shops, trimmings from die forging, sprue, risers and gates from foundry shops, all could constitute scrap piles which could be remelted and reused in production line. Induction furnace is found suitable in achieving this aim because of its traditional moderate size and environmental friendliness, making its movement easy. The heat needed to generate melt is itself generated within the scrap electromagnetically- a non-contact heating process. High frequency electricity drives a large alternating current through a coil which in turn generates a very intense and rapidly changing magnetic field (causing eddy current in the scrap). In other to achieve time-gain melting exercise, part of the subsequent melt is left in the furnace as "heel" to preheat the next charged solid scrap. This work is aimed at determination of most economic, optimum, level of charge and heel in the routine melting. 


\subsection{Literature Review}

\subsubsection{Electromagnetic induction heating}

Induction heating is mainly dependent on two physical phenomena:

1. Faraday-Lenz's law and

2. The Joule effect

When loop of a conductor is placed in an alternating magnetic field, alternating current is induced in the loop thus

$$
\mathbf{E}=\frac{d \Phi}{d t}
$$

Where $\mathbf{E}=$ voltage $(\mathrm{v})$

$\Phi=$ magnetic flux $(\mathrm{wb})$

$\mathrm{t}=$ time $(\mathrm{s})$

Faraday affirmed that when this loop is short-circuited, the induced voltage ' $\mathbf{E}$ ' will cause current to flow and oppose its cause, the alternating magnetic field. If a massive conductor (like a charged crucible) is placed in the alternating magnetic field, eddy current will be induced and in turn, generate heat within the conductor according to the joule effect principle. [1]

\subsubsection{The Joule effect}

When current 'I' (A) flows through a conductor with resistance 'R' $(\Omega)$, power 'p' (w) is dissipated in the conductor as [2]:

$$
\mathbf{P}=\mathrm{R} \times \mathrm{I}^{2}
$$

\subsubsection{Skin effect}

A source of high frequency electricity is used to drive a large alternating current through the coil. This coil is known as the work coil (Figure 1). The passage of current through this coil generates a very intense and rapidly changing magnetic field in the space within the work coil. The work piece to be heated is placed within this intense alternating magnetic field. The alternating magnetic field induces a current flow in the conductive work piece. The arrangement of the work coil and the work piece can be thought of as an electrical transformer. The work coil is like the primary where electrical energy is fed in, and the work piece is like a single turn secondary that is short-circuited. This causes tremendous currents to flow through the work piece. These are known as eddy currents.(Figure 2). In addition to this, the high frequency used in induction heating applications gives rise to a phenomenon called skin effect. This skin effect forces the alternating current to flow in a thin layer towards the surface of the work piece. The 
skin effect increases the effective resistance of the metal to the passage of the large current. Therefore it greatly increases the heating effect caused by the current induced in the work piece. So, the skin effect is characterized by a parameter called penetration depth $(\delta \mathrm{in} \mathrm{mm})$ to estimate the induced eddy current penetration depth. Maxwell's equation gives $\delta$ as

$$
\delta=k \sqrt{\rho / \mu_{r} f}
$$

Where ' $\rho$ ' = electrical resistivity $(\Omega . m)$

$\mu_{\mathrm{r}}=$ relative magnetic permeability $(\mathrm{H} / \mathrm{m})$

$\mathrm{f}=$ frequency $(\mathrm{Hz})$ and

$\mathrm{k}=$ proportionality constant (503 for steel) [3]

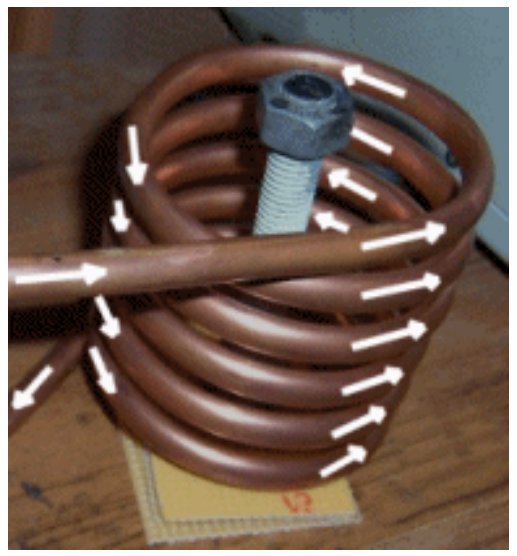

Figure 1. Skin effect demonstration on the surface of the heated bolt(www.inductionheating.co.uk )

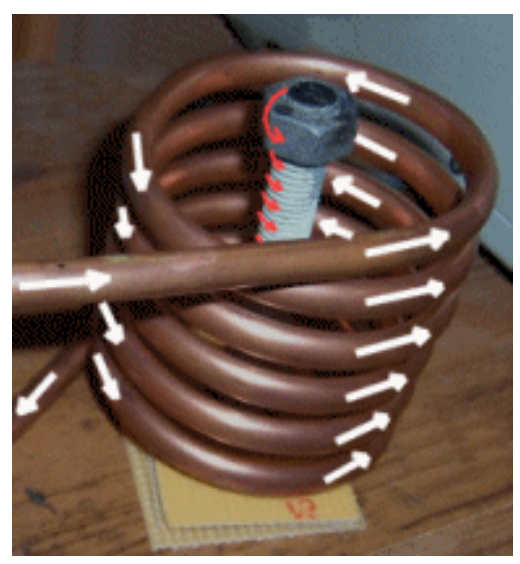

Figure 2: Eddy current concentrates on the surface of the work piece 


\subsection{Induction Furnace Heat Generation}

\subsubsection{Heat generation rate in an induction furnace}

The heat ' $Q$ ' in joule, generated in an induction furnace is directly proportion to the square of the induced current ' ${ }_{\mathrm{s}}^{\mathrm{s}}$ ' in Ampere, as shown in equation 3.

$$
Q=Z I_{s}^{2}\left(\sqrt{\mu_{r} \rho f}\right) \bullet t
$$

Heat generation rate is therefore given by

$$
Q / t
$$

where $\mathrm{Z}=$ an empirical constant [4].

The induction furnace arrangement behaves likes a transformer. The work coil is likened to the primary winding while the charge serves as secondary winding [5].

\subsubsection{The Heat $\left(H_{s}\right)$ needed to melts solid scrap of mass $m_{s}$ in $\mathrm{Kg}$ and raise the melt temperature from ambient temperature to a superheat temperature $\theta_{s}$ in ${ }^{\circ} \mathrm{C}$.}

Heat $H_{s}$ shall be the addition of heat to raise the scrap's temperature from ambient temperature to its melting point, heat needed to change the solid scrap to liquid at the same temperature and the heat needed to raise the temperature of the melt from melting point to a given superheat temperature. Thus,

$$
H_{s}=m_{s} C\left(\theta_{m}-\theta\right)+m_{s} L+m_{s} C\left(\theta_{s}-\theta_{m}\right)
$$

Where $\mathrm{C}=$ specific heat capacity of the scrap material in ....

$\theta_{m}=$ melting point of the scrap material

$\theta=$ ambient temperature

The heat contents of heel and the mixture (solid scrap and heel) are connoted as $\mathrm{H}_{\mathrm{h}}$ and $\mathrm{H}_{\mathrm{mx}}$ respectively (equation 5 and 6 )

$$
H_{h}=m_{h} C \theta_{m}+m_{h} L+m_{h} C\left(\theta_{s}-\theta_{m}\right)
$$




$$
H_{m x}=\left(m_{s}+m_{h}\right) C \theta_{m x}
$$

(The resulting mixture is assumed to be is solid form, else the model does not apply).

Similarly, $\mathrm{H}_{\mathrm{mx}}$ can be written as

$$
H_{m x}=m_{s} C \theta+m_{h} C \theta_{m}+m_{h} L+m_{h} C\left(\theta_{s}-\theta_{m}\right)
$$

Then,

$$
\theta_{m x}=\frac{m_{s} C \theta+m_{h} L+m_{h} C \theta_{s}}{C\left(m_{h}+m_{s}\right)}
$$

Where $\theta_{m x}=$ mixture's temperature.

The crucible effective mass $m_{e f f}=m_{s}+m_{h}$.

\section{THE MODEL EQUATIONS}

\section{Assumptions:}

1. Heat loss during opening and closing of the furnace is neglected

2. The heat absorbed by the crucible (during the first melting) is not accounted for.

To have a complete melt from the scrap, the inductive heat generated by the furnace must be equal to the heat needed to melt the scrap.

Therefore, $Q=H_{s}$.

That is,

$$
Z I_{s}^{2}\left(\sqrt{\mu_{r} \rho f}\right) \bullet t=m_{s} C\left(\theta_{m}-\theta\right)+m_{s} L+m_{s} C\left(\theta_{s}-\theta_{m}\right)
$$

And

$$
t=\frac{m_{s} C\left(\theta_{m}-\theta\right)+m_{s} L+m_{s} C\left(\theta_{s}-\theta_{m}\right)}{Z I_{s}^{2}\left(\sqrt{\mu_{r} \rho f}\right)}
$$

\section{THE MODEL PROGRAM}

\section{CLS}

10 REM "MODEL PROGRAMME FOR OPTIMIZING SCRAP -HEEL LEVEL 
$20 \mathrm{DIM} \mathrm{M}_{\text {heel }}(200), \mathrm{M}_{\text {scrap }}(200), \mathrm{T}_{\mathrm{mx}}(200), \mathrm{Q}_{\mathrm{m}}(200), \operatorname{COST}_{\mathrm{s}}(200), \operatorname{COST}_{\mathrm{h}}(200), \mathrm{G}(200), \mathrm{T}_{\text {hr }}(200)$

$35 \mathrm{DIM} \mathrm{Q}_{1}(200), \mathrm{Q}_{2}(200), \mathrm{Q}_{3}(200), \mathrm{C}_{\mathrm{s}}(200), \mathrm{C}_{\mathrm{t}}(200), \mathrm{C}_{\mathrm{h}}(200), \mathrm{C}_{\mathrm{sh}}(200), \mathrm{COST}_{\mathrm{s}} 1 \mathrm{Kg}(200)$

$40 \operatorname{DIM~COST}_{\mathrm{h}} 1 \mathrm{Kg}$ (200), $\operatorname{COST}_{\text {melt }}$ (200), G (200), J (200), Pp (200), NS (200), LS(200)

50 REM " $\rho$ s" IS CHARGE MATERIAL DENSITY; "V $\mathrm{V}_{\text {cru }}$ AND " $\mathrm{V}_{\text {eff" }}$ " ARE TOTAL AND EFFECTIVE VOLUMES IN RESPECTIVELY

55 REM "M $\mathrm{M}_{\mathrm{eff}}$ IS EFFECTIVE MASS OF CHARGE"

60 INPUT "CHARGE DENSITY $=$ "; $\rho_{S}$

$70 \mathrm{~V}_{\text {cru }}=0.003825: \mathrm{V}_{\text {eff }}=(3 / 4) * \mathrm{~V}_{\text {cru }}: \mathrm{M}_{\text {eff }}=\rho_{\mathrm{al}} * \mathrm{~V}_{\text {eff }}$

75 PRINT "EFFECTIVE MASS = "; $\mathrm{M}_{\text {eff }}$

$\mathrm{a} \$=\operatorname{INPUT} \$(1)$

80 REM "C" IS SPECIFIC HEAT CAPACITY OF THE STEEL; "L" IS LATENT HEAT

OF FUSION OF THE STEEL AS WELL"

90 REM “ $T_{\text {amb }}$ " IS THE AMBIENT TEMPERATURE; “ $T_{\mathrm{m}}$ ” IS MELTING POINT OF THE

ALLOY (THE STEEL); AND“T,"IS THE SUPERHEATTEMPERATURE

100 INPUT "C="; C

105 INPUT "L"; L

110 INPUT " $\mathrm{T}_{\mathrm{amb}}=$ "; $\mathrm{T}_{\mathrm{amb}}$

115 INPUT " $\mathrm{T}_{\mathrm{s}}=$ "; $\mathrm{T}_{\mathrm{s}}$

120 REM “IP" IS THE SUPPLIED CURRENT IN AMP. ; “V”, "IS THE SUPPLIED

VOLTAGE IN VOLT AND “ $\mu \mathrm{r}$ ” THE ALLOY'S RELATIVE MAGNETIC

PERMIABILITY,"F"IS FREQUENCY AND"LS”IS THE INDUCED CURRENT

$125 \mathrm{I}_{\mathrm{P}}=16.3: \mathrm{V}_{\mathrm{P}}=170: \mu \mathrm{r}=180: \mathrm{F}=50: \mathrm{KT}=0.0013$

130 REM HEEL RANGES FROM 10\% TO 50\% STEP 5 WHILE SCRAP RANGES FROM 90\% TO 50\% STEP 5

135 REM " $R_{\text {sc }}$ " IS SCRAP RANGE; " $R_{\text {heel }}$ " IS HEEL RANGE; " $M_{\text {heel }}$ " IS MASS OF HEEL;

“M $\mathrm{M}_{\text {scrap }}$ " IS MASS OF SCRAP $\mathrm{a} \$=\operatorname{INPUT} \$(1)$

$140 \mathrm{I}=1$

$145 \mathrm{R}_{\mathrm{sc}}=0.9$

150 FOR $R_{\text {heel }}=0.1$ TO 0.50 STEP 0.05

$155 \mathrm{M}_{\text {heel }}=\mathrm{M}_{\text {eff }} * \mathrm{R}_{\text {heel }}$

$160 \mathrm{M}_{\text {scrap }}=\mathrm{M}_{\mathrm{eff}} * \mathrm{R}_{\mathrm{sc}}$

$165 \mathrm{Q}_{1}=\mathrm{M}_{\text {scrap }} * \mathrm{C}^{*} \mathrm{~T}_{\mathrm{amb}}$

$170 \mathrm{Q}_{2}=\mathrm{M}_{\text {heel }} * \mathrm{~L}$

$175 \mathrm{Q}_{3}=\mathrm{M}_{\text {heel }} * \mathrm{C} * \mathrm{~T}_{\mathrm{s}}$

$180 \mathrm{Tmx}=\left(\mathrm{Q}_{1}+\mathrm{Q}_{2}+\mathrm{Q}_{3}\right) /\left(\mathrm{C} * \mathrm{M}_{\mathrm{eff}}\right)$

$185 \mathrm{G}=\mathrm{KT}^{*}(\mathrm{LS})^{\wedge} 2$

205 IF Tmx $>200$ AND Tmx $<250$ THEN PC $=0.296$ ELSE

IF Tmx $>250$ AND Tmx $<350$ THEN PC $=0.301$ ELSE

IF Tmx $>350$ AND Tmx $<400$ THEN PC $=0.493$ ELSE 
IF Tmx $>400$ AND Tmx $<500$ THEN PC $=0.638$ ELSE

IF Tmx $>500$ AND Tmx $<600$ THEN PC $=0.739$ ELSE

IF Tmx $>600$ AND Tmx $<700$ THEN PC $=0.894$ ELSE

IF Tmx $>700$ AND Tmx $<800$ THEN PC $=1.06$ ELSE

IF Tmx $>800$ AND Tmx $<900$ THEN PC $=1.093$ ELSE

IF Tmx $>900$ AND Tmx $<1000$ THEN PC $=1.11$ ELSE

IF Tmx $>1000$ AND Tmx $<1100$ THEN PC $=1.142$ ELSE

IF Tmx $>1100$ AND Tmx $<1200$ THEN PC $=1.169$ ELSE 295

$$
\mathrm{a} \$=\operatorname{INPUT} \$(1)
$$

$208 \mathrm{~J}=\left(\mu \mathrm{r} * \mathrm{PC}^{*} \mathrm{~F}\right)^{\wedge} 0.5$

$210 \mathrm{Pp}=\mathrm{G}^{* \mathrm{~J}}$

$213 \mathrm{t}=\left(\left(\mathrm{M}_{\text {scrap }} * \mathrm{C} * 1350\right)+\left(\mathrm{M}_{\text {scrap }} * \mathrm{~L}\right)+\left(\mathrm{M}_{\text {scrap }} * \mathrm{C} * 125\right)\right) / \mathrm{Pp}$

215 REM " $\mathrm{T}_{\mathrm{hr}}$ IS THE TIME REQUIRED IN HOUR TO MELT THE SCRAP" $220 \mathrm{~T}_{\mathrm{hr}}=\mathrm{t} / 3600$

225 REM "NEPArate IS COST IN NAIRA PER KWh"

230 REM " $\mathrm{Q}_{\mathrm{m}}$ IS THE ENERGY USEDE TO MELT SCRAP IN KILOWATT"

$235 \mathrm{Q}_{\mathrm{m}}=\left(\mathrm{I}_{\mathrm{p}} * \mathrm{~V}_{\mathrm{p}} * \mathrm{~T}_{\mathrm{hr}}\right) / 1000$

240 NEPArate $=6$

245 REM "COSTs" IS OF MELTING SCRAP

$250 \operatorname{COST}_{\mathrm{S}}=6 * \mathrm{Q}_{\mathrm{m}}$

$255 \operatorname{COSTs} 1 \mathrm{Kg}=\operatorname{COSTs} / \mathrm{M}_{\text {scrap }}$

260 PRINT "COST OF MELTIN 1Kg SCRAP”; “=”; COSTs1Kg

265 PRINT "MASS OF SCRAP IN Kg="; scrap

270 PRINT “MASS OF HEEL IN Kg="; M heel

275 PRINT "TIME TAKEN TO MELT THE SCRAP IN HOUR="; $\mathrm{T}_{\mathrm{hr}}$ 280 PRINTS “TEMP. OF THE CHARGE Tmx IN DEGREE CELCIUS = "; Tmx $283 \mathrm{I}=\mathrm{I}+1$

$285 \mathrm{Rsc}=\mathrm{R}_{\mathrm{sc}}-0.5$

289 PRINT “ ,

290 NEXT $R_{\text {heel }}$

$a \$=I N P U T \$(1)$

295 END

RUN

COST OF MELTING 1Kg SCRAP $=0.88$

MASS OF SCRAP IN Kg $=19.1$

MASS OF HEEL IN $\mathrm{Kg}=3.38$

TIME TAKEN TO MELT THE SCRAP IN HOUR $=1.01$

TEMP. OF THE CHARGE Tmx IN DEGREE CELCIUS $=301.93$ 
COST OF MELTING $1 \mathrm{Kg}$ SCRAP $=0.69$

MASS OF SCRAP IN Kg $=18.0$

MASS OF HEEL IN $\mathrm{Kg}=4.5$

TIME TAKEN TO MELT THE SCRAP IN HOUR $=0.75$

TEMP. OF THE CHARGE Tmx IN DEGREE CELCIUS = 394.24

\section{EXPERIMENTAL PROCEDURE}

- Scrap was sourced locally, sorted and weighed in different quantities

- First charging for initial heel-gain

- Sequential charge melting

- Furnace clean up and turning off.

( Yusuf, 1998 )

\section{RESULTS AND DISCUSSION}

\subsection{Model Result}

The induction furnace model result is presented in Table 1.

Table 1: model results.

\begin{tabular}{lllll}
\hline SN & $\mathbf{M}_{\text {scrap }(\mathrm{Kg})}$ & $\mathbf{M}_{\text {heel(Kg }}$ & $\begin{array}{l}\text { COST, 1Kg } \\
\text { SCRAP(N) }\end{array}$ & $\begin{array}{l}\text { TIME TO } \\
\text { MELT } \\
\mathbf{M}_{\text {scrap }}(\text { Hr })\end{array}$ \\
\hline 1 & 20.25 & 2.50 & 0.89 & 1.08 \\
\hline 2 & 19.13 & 3.38 & 0.88 & 1.02 \\
\hline 3 & 18.00 & 4.50 & 0.69 & 0.75 \\
\hline 4 & 16.88 & 5.63 & 0.61 & 0.62 \\
\hline 5 & 15.75 & 6.75 & 0.56 & 0.53 \\
\hline 6 & 14.63 & 7.87 & 0.51 & 0.45 \\
\hline 7 & 13.50 & 9.00 & 0.47 & 0.38 \\
\hline 8 & 12.38 & 10.13 & 0.46 & 0.35 \\
\hline
\end{tabular}

\subsection{Experimental Results}

The experimental result is presented in Figure 3. 


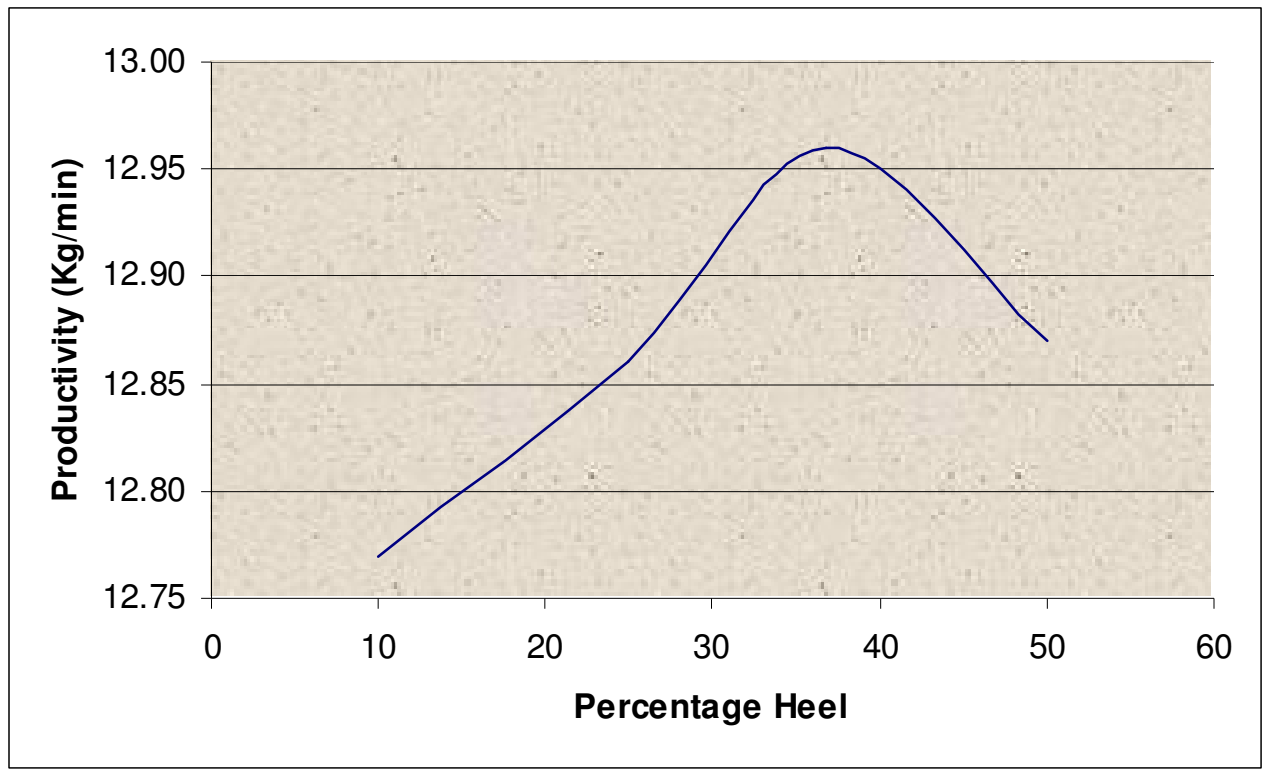

Figure 3. Percentage Heel against Productivity

\subsection{Results Discussion}

The productivity increased with increase in heel level. Above $36.8 \%$ heel level however, a steep decline in productivity set in (Figure 3). From the model result (table4.1), increase in heel level up to $9.00 \mathrm{Kg}$ caused remarkable reduction in energy-cost of melting. Further increase above this level however caused no significant reduction in energy-cost of melting.

\section{CONCLUSION}

Optimum range of melting the medium carbon steel in term of charge/heel ratio is between 3: 2 and 6.3: 3.7 by mass.

\section{REFERENCES}

1. Callebant L. (2007) "Induction Heating". Pp2-9. www.induction .com.

2. Theraja B.L. and Theraja A.K. (2002) "Electrical Technology" S.chand New Delhi. 926pp;Pp1479-1490

3. Sybil P.P., Jonathan W. and Betty R. (1982) "Encyclopedia of Science and Technology" Mc Graw-Hill New York 608pp, vol 3; 432pp vol 12

4. Rock H. (2003) "Induction Heating Plus" Thermal corporate, Pp1-3

5. www.inductionheating.co.uk

6. Yusuf J.A. (1998) "investigation on the effect of cold charge and heel on the productivity of foundry furnace and effect on the quality of product" Pp6-28 